\title{
The RaDiCEA Project: cost of illness (COI) analysis applied to Cryopyrin Associated Periodic Syndromes (CAPS)
}

\author{
O Della Casa Alberighi ${ }^{1}$, L Trieste ${ }^{2}$, L Accame ${ }^{1}$, V Lorenzoni ${ }^{2}$, F Pierotti ${ }^{2}$, S Federici ${ }^{3 *}$, M Gattorno ${ }^{3^{*}}$, P Quartier $^{4}$, \\ P Duong Ngoc ${ }^{4}, \mathrm{~N}$ Cabrera Rojas ${ }^{4}$, A Martini $^{3}, \mathrm{G}$ Turchetti ${ }^{2}$
}

From 8th International Congress of Familial Mediterranean Fever and Systemic Autoinflammatory Diseases Dresden, Germany. 30 September - 3 October 2015

\section{Introduction}

When a disease affects only a few individuals in each country (ultra-orphan disease), it can be very hard to establish the costs of illness (COI) and the cost-effectiveness (CE) of treatments (ultra-orphan drugs). Conventional methods for $\mathrm{COI}$ and $\mathrm{CE}$ of drugs for common conditions do not apply, and additional factors need to be considered. As expensive medications (biologicals) show promising results, it becomes crucial to have detailed information on as many patients as possible.

\section{Objectives}

This international, multicenter, longitudinal observational COI and CE study will evaluate the burden of CAPS in terms of direct and indirect costs and quality of life (QoL). The COI analysis implies the identification, quantification and evaluation of resources from a societal perspective.

\section{Materials and methods}

In the frame of the EuroFever registry (http://www. printo.it/eurofever/), 8 Centers of reference for autoinflammatory diseases in Italy and France (sentinel countries) are currently enrolling all consenting/assenting CAPS adult patients and children with the indication for either the use of an anti IL-1 agent or other than anti IL-1 therapies (NSAIDs, systemic corticosteroids, immunosuppressive drugs), and compliant to the study. To perform the COI analysis, clinical and economic data are collected at country-specific- and general levels, both retrospectively (since disease onset) and prospectively (from study enrollment to the last visit) by mean

\footnotetext{
${ }^{3}$ Istituto di Ricovero e Cura a Carattere Scientifico (IRCCS) Giannina Gaslini, Pediatria II, Reumatologia, Genova, Italy

Full list of author information is available at the end of the article
}

of general questionnaires administered to patients or their proxy on direct medical and non-medical costs, and indirect costs of productivity loss. QoL is prospectively measured using EQ5D to estimate utility score and calculate QALY.

\section{Results}

COI analysis results based on the Italian and French Healthcare Systems will test the robustness of the proposed methodology, assumptions and source of data before a generalization to other countries. To properly value the used resources, country-specific questionnaire administered to the budget and management control officer at each center will collect information about the healthcare system type, hospitalization reimbursement system, out of hospitalization drug payment, payment of special schools and devices, application of exemption, disability pension and/or allowance for caregivers. All costs will be referred to a common base year and adjusted to eliminate the effect of inflation. The differences in price levels between countries will be eliminated applying the Purchase Power Parities using Euros as the reference base.

\section{Conclusion}

The ERANET-PRIOMEDCHILD RaDiCEA Project (No. 40-41800-98-007) will develop a model to evaluate costs and long-term benefits in an ultra-orphan group of diseases such as CAPS. The same model may be used in other very rare disorders.

\section{Authors' details}

${ }^{1}$ Istituto di Ricovero e Cura a Carattere Scientifico (IRCCS) Giannina Gaslini, Unità di Farmacologia Clinica e Sperimentazioni Cliniche, Direzione 
Scientifica, Genova, Italy. ${ }^{2}$ Scuola Superiore Sant'Anna, Institute of Management, Pisa, Italy. ${ }^{3}$ Istituto di Ricovero e Cura a Carattere Scientifico (IRCCS) Giannina Gaslini, Pediatria II, Reumatologia, Genova, Italy. ${ }^{4}$ Assistance Publique-Hopitaux de Paris Hopital Necker, Paediatric Immunology, Haematology and Rheumatology Unit, Paris, France.

Published: 28 September 2015

doi:10.1186/1546-0096-13-S1-P186

Cite this article as: Della Casa Alberighi et al:: The RaDiCEA Project: cost of illness (COI) analysis applied to Cryopyrin Associated Periodic Syndromes (CAPS). Pediatric Rheumatology 2015 13(Suppl 1):P186.

Submit your next manuscript to BioMed Central and take full advantage of:

- Convenient online submission

- Thorough peer review

- No space constraints or color figure charges

- Immediate publication on acceptance

- Inclusion in PubMed, CAS, Scopus and Google Scholar

- Research which is freely available for redistribution

Submit your manuscript at www.biomedcentral.com/submit 